\title{
ACARPA e CLUBES 4-S: a modernização da agricultura em Marechal Cândido Rondon/PR (1960-1970)
}

Cíntia Wolfart ${ }^{1}$

Resumo: A cidade de Marechal Cândido Rondon está inserida numa região com alto índice populacional rural e tem uma economia com forte relação com a agricultura. Pode-se dizer que o Oeste do Paraná é um pólo da agroindústria ou agronegócio. Denota-se isso em diversos eventos e reuniões que possuem como tema o agronegócio. Esta região recebeu volumosos incentivos à "modernização" da agricultura por parte do Estado, por meio de instituições governamentais como a Acarpa (Emater), bem como, por organizações não governamentais, cooperativas, como a Copagril, além dos sindicatos, associações de produtores rurais, Associações de Jovens Cooperativistas e clubes 4-S. Esta rede conta com canais de difusão, que são os jornais locais e regionais como "Rondon comunicação" e "O Alento", que se responsabilizaram pela disseminação de um determinado tipo de conceito de desenvolvimento para este território. Neles é possível observar intensas propagandas movidas pelas instituições no que dizia respeito a execuções de políticas voltadas para "modernização" da agricultura nesta região. Este artigo apresenta elementos de análise sobre a influência da Acarpa e dos clubes 4-S para a "modernização" da agricultura em Marechal Cândido Rondon presentes nos jornais de circulação na cidade entre os anos de 1960 e 1970.

Palavras - Chave: Oeste do Paraná; Modernização agrícola; Estado.

Abstract: The city of Marechal Cândido Rondon is embedded in a region with high rural population index and has an economy with strong connection with agriculture. It can be said that the West of Paraná is a hub of agribusiness. We can notice this based on various events and

${ }^{1}$ Graduada em História pela Universidade Estadual do Oeste do Paraná - UNIOESTE. 
meetings that discuss and talk about the agribusiness themes. This region received massive incentives to "modernization" of agriculture by the state, through government institutions like Acarpa (Emater), as well as by non-governmental organizations, cooperatives, as Copagril, beyond the trade unions, associations of farmers, Youth Cooperativists Associations and 4-S Clubs. This network count with broadcast channels, which are local and regional newspapers as "Rondon comunicação" (Rondon Communication) and "O Alento" (The Breath), which were responsible for the spread of a particular type of concept for this area. In them it can be observed intense advertisements filed by institutions in regard to execution of policies for "modernization" of agriculture in this region. This article gives an analysis on the influence of Acarpa and 4-S Clubs for the "modernization" of agriculture in Marechal Cândido Rondon present in circulation newspapers in the city between 1960 and 1970.

Keywords: West of Paraná; Agricultural modernization; State

\section{A "modernização" da agricultura no Oeste do Paraná,} especificamente no município de Marechal Cândido Rondon, é um fenômeno relativamente recente. É a partir dos anos de 1960 que algumas empresas, como a Copagril ${ }^{2}$ conjuntamente com instituições como a Acarpa $^{3}$ e os clubes $4-\mathrm{s}^{4}$, buscaram desenvolver uma maior

${ }^{2}$ Cooperativa Agroindustrial - COPAGRIL.

${ }^{3}$ De acordo com o site da Emater (Empresa de Assistência Técnica e Extensão Rural) a ACARPA (Associação de Crédito e Assistência Rural do Paraná) foi uma organização que liderou o processo de difusão de tecnologia nesta região a partir de 1959. Os extensionistas desenvolveram junto com agricultores práticas de implantação e manejo de lavouras e criações, estratégias de controle de pragas, sistemas e processos de manejo e conservação de solos tendo como objetivo o crescimento da produtividade. Disponível no site:

http://www.emater.pr.gov.br/modules/conteudo/conteudo.php?conteudo=43\%20acess ado $\% 20 \mathrm{em} \% 202 \% 20 \mathrm{de} \% 20 \mathrm{Janeiro} \% 20 \mathrm{de} \% 202014$ acessado em 11 de julho de 2014. ${ }^{4}$ Segundo Leonardo Ribeiro Gomes em seu artigo intitulado "O Jovem dos Clubes 4S como elemento difusor da Modernização das Práticas agrícolas em Minas Gerais nas 
racionalização do empreendimento com incorporação de inovações técnicas e sofisticados métodos de preparo e cultivo do solo, além de processos de colheitas e plantios adequados a esta etapa da produção capitalista.

Segundo dados do IBGE, o município de Marechal Cândido Rondon foi colonizado na década de 1950 pela Industrial Madeireira Colonizadora Rio Paraná - MARIPÁ. O Distrito, denominado General Rondon, foi oficialmente criado em 1953 e era subordinado ao município de Toledo. Somente em 1960 Marechal Cândido Rondon foi constituído como município e desmembrado, oficialmente, de Toledo. Faziam parte de seu território os seguintes distritos: Margarida, Pato Bragado, Entre Rios do Oeste, Mercedes, Porto Mendes e Quatro Pontes. Atualmente, compõem a seara do município os seguintes distritos: Bom Jardim, Iguiporã, Margarida, Novo Horizonte, Novo Três Passos, Porto Mendes e São Roque. ${ }^{5}$

décadas de 1950 e 1960" os 4 "S" significavam: Saber, Sentir, Saúde e Servir. A organização e formação dos Clubes 4-S em Minas Gerais mantinha estreita relação com o debate sobre Educação Rural das décadas de 1940 e 1950 naquela região, envoltas na discussão sobre o desenvolvimento e modernização econômica preconizada para áreas consideradas subdesenvolvidas. GOMES, Leonardo Ribeiro. O Jovem dos Clubes 4-S como elemento difusor da Modernização das Práticas agrícolas em Minas Gerais nas décadas de 1950 e 1960 Faculdade de Educação - UFMG. 11p.

Artigo disponível no site http://sbhe.org.br/novo/congressos/cbhe7/pdf/04$\% 20$ HISTORIA $\% 20$ DA $\% 20$ EDUCACAO $\% 20$ DAS\%20CRIANCAS-

\%20JOVENS\%20E\%20ADULTOS\%20NO\%20BRASIL/O\%20JOVEM\%20DOS\%2 0CLUBES\%204-S.pdf acessado em 11 de julho de 2014.

${ }^{5}$ Dados disponíveis no site do IBGE:

http://cidades.ibge.gov.br/painel/historico.php?lang=\&codmun=411460\&search=para na|marechal-candido-rondon|infograficos:-historico acessado em 29 de Janeiro de 2014. 
Marechal Cândido Rondon é tradicionalmente apresentado como uma região cuja economia se baseia na agropecuária (soja, milho, trigo, mandioca, fumo, feijão, frutas, café, aves, suínos, vaca de leite). O modo de vida relacionado ao desenvolvimento da agricultura nesta região possui características de trabalho familiar. Segundo dados do IBGE, do censo agrícola do ano 2012, a soja e o milho são os grãos cultivados em maior quantidade no município. O número de áreas plantadas e colhidas que produzem o milho em lavoura temporária é de 29.400 hectares e geram, aproximadamente, 144.800 toneladas. Com relação à soja, o número de áreas plantadas e colhidas é de 26.100 hectares. Estas propriedades geram aproximadamente uma quantidade de 35.558 toneladas do produto em lavoura temporária. ${ }^{6}$ Marechal limita-se ao norte com o município de Mercedes, ao nordeste com Nova Santa Rosa, a leste com Quatro Pontes, a sudeste com Toledo e Ouro Verde do Oeste, a sudoeste com Pato Bragado, ao sul com São José das Palmeiras e Entre Rios do Oeste.

Nesta região, a agricultura é uma atividade que se constitui como fonte de vida e de trabalho para um número considerável de habitantes, o próprio processo de "modernização" modificou intencionalmente esta realidade. A mecanização representou a diminuição de parte significativa de postos de emprego rural e afetou a

\footnotetext{
${ }^{6}$ Os dados do IBGE podem ser visualizados no site: http://www.cidades.ibge.gov.br/xtras/temas.php?lang=\&codmun=411460\&idtema=12 $3 \&$ search=parana|marechal-candido-rondon|lavoura-temporaria-2012 acessado em 25 de Janeiro de 2014.
} 
população com o movimento e trânsito de agricultores com o êxodo rural. Esta realidade estabeleceu novas dinâmicas ao perfil regional.

Como mencionado no início deste artigo, a discussão sobre a chamada "modernização" da agricultura foi amplamente divulgada em alguns jornais da região que registraram a construção histórica ora mencionada. Esta pesquisa que se encontra em sua fase inicial, apresenta alguns resultados a partir da análise de alguns fragmentos presentes nos referidos jornais locais. Trata-se de um acervo que, na atualidade, pode constituir em um rico material para o estudo e quantificação desta realidade. Esses periódicos, principal fonte histórica para esta pesquisa se localizam no Centro de Documentação do Oeste do Paraná (CEPEDAL), na Universidade Estadual do Oeste do Paraná, campus de Marechal Cândido Rondon. Pode-se dizer que, os meios de informação da época, principalmente o rádio e os jornais diários locais, foram importantes veículos de difusão das novas estratégias produtivas destinadas aos agricultores. De fontes de informações, hoje este material constitui possibilidade de fonte histórica.

Nestas fontes pesquisadas, como por exemplo, o jornal " $O$ Alento", observam-se informações relacionadas ao êxodo rural no Paraná, demonstrando certa preocupação com relação a este contexto. $\mathrm{O}$ referido jornal apresenta dados desta realidade que possibilitam supor que a "modernização" agrícola impactou diretamente os trabalhadores rurais. Podendo, inclusive, ser um fator que levou muitos desses 
trabalhadores a buscarem outras possibilidades de trabalho, em outros lugares.

Em Curitiba, o Departamento de Pesquisa da Federação dos Trabalhadores na Agricultura no Estado do Paraná fez um levantamento das favelas e constatou a seguinte realidade: mais de $90 \%$ dos moradores procedem do campo e nos onze mil barracos que cercam a capital, residem nada menos de 88 mil agricultores, hoje favelados (CEI, n. 146, Janeiro de 1979, pag.9). A pesquisa está sendo feita para apurar as causas do êxodo rural e da marginalização urbana. ${ }^{7}$

Trata-se de um dado relevante, mas não definitivo. Embora elaborado com o objetivo de incluir certa dose de objetividade sobre um aspecto específico da vida nas zonas periféricas de grandes cidades, não se pode deixar de levar em consideração outros fatores.

Sirlei de Fátima de Souza, em sua dissertação de mestrado intitulada "Tradição X Modernização no Processo Produtivo Rural: Os Clubes 4-S em Passo Fundo (1950-1980)", realizou uma abordagem sobre os conflitos que, de forma direta e indireta, estavam atrelados ao processo de modernização da agricultura em Passo Fundo e seus desdobramentos com relação aos trabalhadores rurais.

Segundo de Souza,

\footnotetext{
${ }^{7}$ Jornal "O Alento". Marechal Cândido Rondon, Ano: I; Número: 12. Data: 13/10 À 18/10/79; Assunto: Êxodo Rural. Jornal disponível para consulta no Centro de Documentação do Oeste do Paraná - CEPEDAL, localizado na Universidade Estadual do Oeste do Paraná - UNIOESTE, no campus de Marechal Cândido Rondon.
} 
Com o processo de modernização agrícola, a pequena propriedade passou por reestruturações (...), e a terra, bem como a maneira de nela produzir, passou a ter um custo elevado, exigindo investimentos financeiros e orientações técnicas, o que, por consequência, levou a um maior contato com o meio urbano e também provocou o êxodo rural. $^{8}$

A "modernização" da agricultura, nos termos mencionados, pode ser definida, segundo Argemiro Jacob Brum ${ }^{9}$, como um processo através do qual ocorrem modificações na base técnica da produção, bem como, modificações nas relações sociais de produção, cujo objetivo principal da produção agropecuária passou a ser somente o lucro. No entanto esse fenômeno deve ser percebido dentro do contexto da economia mundial e da estratégia de sua expansão no pós-guerra. ${ }^{10}$

Nesse sentido, para Argemiro Brum, a "modernização" da agricultura no Brasil esteve ligada a mudanças econômicas ocorridas no mundo pós Segunda Guerra Mundial, momento em que os Estados Unidos se consolidaram como potência hegemônica no mundo capitalista - ainda que rivalizasse com o socialismo da URSS durante a chamada guerra fria - e provedor de recursos materiais e intelectuais

\footnotetext{
${ }^{8}$ SOUZA, Sirlei de Fátima. Tradição x modernização no processo produtivo rural: os Clubes 4-S em Passo Fundo (1950-1980). Dissertação (Mestrado na área de História Regional) - Universidade de Passo Fundo. Rio grande do Sul, 2003, p.68. ${ }^{9}$ BRUM, Argemiro Jacob. Modernização da Agricultura: Trigo e Soja. Ijuí, RS, 1988.

${ }^{10}$ BRUM,1988,p. 66.
} 
para a reconstrução dos países diretamente envolvidos no contexto da guerra. Esse evento alterou profundamente a estrutura do poder econômico mundial e coincide com o período em que a hegemonia das grandes corporações transnacionais, ou multinacionais, e a integração econômica mundial, subordinou e transformou agências do Estado em executores de seus interesses. ${ }^{11}$

Tanto Argemiro Brum, quanto Clovis Tadeu Alves analisaram o processo da "modernização" da agricultura no Brasil a partir do contexto pós-Segunda Guerra Mundial. Já outros autores, como Peter Houtzager e Octavio Ianni, analisaram a "modernização" a partir da ditadura civil-militar brasileira (1964-1985). ${ }^{12}$

Segundo Brum, o programa "Revolução Verde" ${ }^{13}$, ainda no decurso da Segunda Guerra Mundial, e durante a ascensão e desenvolvimento da guerra fria, idealizado e patrocinado inicialmente pelo grupo Rockfeller ${ }^{14}$ dos Estados Unidos, teve como objetivo inicial

${ }^{11}$ BRUM, 1988, p. 31,32.

${ }^{12}$ HOUTZAGER, Peter P. Os últimos cidadãos: conflito e modernização no Brasil rural (1964 - 1995). São Paulo, 2004, p. 50.

${ }^{13}$ Ao discutir o conceito de "Revolução Verde", tanto Brum quanto Alves indicam que ela pode ser caracterizada como um "programa orientado e constituído, com o objetivo de aumentar a produção e a produtividade agrícola no mundo. Para isso, desenvolveram novas tecnologias, integrando todo um complexo sistema de apoio. A agricultura não poderia mais ter uma relação social e tradicional do agricultor com a terra e, sim, uma relação complexa entre o agricultor, o mercado financeiro (bancos), a indústria metal-mecânica (maquinas e equipamentos agrícolas), a indústria química (fertilizantes e defensivos agrícolas) e a indústria de pesquisa de tecnologia agrícola." ALVES, Clovis Tadeu. A revolução verde na mesorregião noroeste do RS (19301970). Porto Alegre, 2003, p. 26.

${ }^{14} \mathrm{O}$ poderoso grupo econômico Rockfeller, tinha sua sede em Nova Iorque, nos Estados Unidos. Patrocinou projetos-piloto em determinados países, estratégicamente 
contribuir para o aumento da produtividade agrícola no mundo através de experiências no campo, como a criação de sementes adequadas às condições climáticas e do solo. Além disso, objetivou difundir a descoberta e aplicação de tecnologias mais modernas, fomentadas segundo interesses capitalistas. Apesar de apresentar, em aparência, um apelo humanitário, estes agentes promotores da nova pauta para a agricultura mundial, especificamente aos países compreendidos no raio de influência estadunidense, ocultavam poderosos interesses econômicos e políticos de expansão de grandes corporações. ${ }^{15}$

Com o fim da Segunda Guerra Mundial, portanto, as grandes corporações garantiram a expansão de seu capital através do financiamento e incentivo a "modernização" da agricultura nos países "subdesenvolvidos" ou "países periféricos". No Brasil, a "modernização" da agricultura e a industrialização se iniciaram durante o governo de Getúlio Vargas (1930-1945). Segundo Alves, essas

selecionados, como o México, as Filipinas, o Brasil e Estados Unidos. Nesses países foram realizadas pesquisas e experiências com produtos agrícolas, bem como, desenvolveu-se instervensões controladas no processo de produção agrícola, criteriosamente planejada e habilmente executada pelas grandes corporações. Consultar BRUM, Argemiro Jacob. Modernização da Agricultura: Trigo e Soja. Ijuí, RS, 1988, p. 44,45. Segundo Alves, o direcionamento do capital internacional, especialmente o americano para a agricultura brasileira aprofundou-se com o auxilio da Fundação Rockfeller, principalmente com Nelson. Através da criação de uma instituição filantrópica chamada American International Association for Economic and Social Development (AIA). Esta insituição foi financiadora e pretadora de assistência técnica de programas de extensão rural, como os clubes 4-S no Brasil. Consultar ALVES, Clovis Tadeu. A Revolução Verde na mesorregião Noroeste do RS (1930-1970). Porto Alegre, 2013.

${ }^{15}$ BRUM, 1988, p. 44. 
décadas são marcadas por "problemas agrícolas" no país, fruto das condições climáticas e pela dificuldade interna em suprir a demanda dos produtos da agricultura de clima temperado, além de excesso de oferta da agricultura de clima tropical. Deste modo, o Estado procurou investir na industrialização, como forma de equilibrar o contexto produtivo, mas especificamente na diversificação de produtos e aumento da produtividade. Para tanto incentivou a importação de uma tecnologia adequada para a agricultura brasileira. ${ }^{16}$

Conforme Brum, o grande impulso dado a "Revolução Verde" ocorreu a partir de $1965,{ }^{17}$ momento em que o Brasil vivia a ditadura civil-militar (1964-1985). Sob a influência das grandes corporações transnacionais e multinacionais, ocorreu certa rearticulação da estratégia da produção de alimentos no mundo. Nesta fase, três fatores se combinaram: a difusão da "Revolução Verde" a nível mundial, a mudança da política econômica de exportações de cereais, introduzida pelo governo estadunidense, chefiado pelo presidente Lindon Johnson e a internacionalização da pesquisa agrícola. ${ }^{18}$

A internacionalização da pesquisa agrícola consistiu em um meio eficiente do processo de "modernização" da agricultura, bem como, um elemento que intensificou a dependência dos países

\footnotetext{
${ }^{16}$ ALVES, 2013, p. 54.

${ }^{17}$ No Brasil os canais da implantação da "Revolução Verde" foram os programas patrocinados pelo governo norte americano: "Aliança para o Progresso" e "Alimentos para a Paz".

${ }^{18}$ BRUM, 1988, p.48.
} 
periféricos em relação às grandes corporações transnacionais que comandavam o processo. No Brasil, durante a década de 1970, reestruturou-se e dinamizou-se o Sistema Nacional de Assistência Técnica e Extensão Rural, através da criação da Empresa Brasileira de Assistência Técnica e Extensão Rural (EMBRATER) vinculada ao Ministério da Agricultura. Este sistema se estendeu por diversos Estados, através da criação da Empresa de Assistência Técnica e Extensão Rural (EMATER). Tal sistema pretendia deter o controle da articulação dos produtores, à iniciação de novas culturas agrícolas, outros procedimentos no campo e orientação alimentar. ${ }^{19}$

Nos anos de 1960 e 1970, surgiram novas formas de reprodução das relações de produção, e novas formas de produzir o espaço agrário no Oeste do Paraná. Nesse período, o Brasil, articulado à economia mundial, desenvolveu políticas que promoveram a expansão do cultivo de trigo e da soja. O objetivo da produção do trigo era diminuir as importações desse produto, e a produção da soja tinha como finalidade a exportação. ${ }^{20}$ Assim, a "modernização" da agricultura na região, ocorreu com a implantação no país de um setor industrial voltado para a produção de equipamentos e insumos para a agricultura.

${ }^{19}$ BRUM, 1988, p. 49.

${ }^{20}$ ZAAR, Miriam Hermi. A produção do espaço agrário da colonização à modernização agrícola e formação do Lago de Itaipu. Cascavel, 1999, p. 29-30. Importante observar que a difusão do consumo do trigo e da soja ocorreu devido à introdução e da consolidação de novos padrões alimentares ditados por alguns países como o dos Estados Unidos. 
A Acarpa articulada a Copagril e a outros grupos, como por exemplo, aos clubes 4-S lideraram o processo de difusão das tecnologias nesta região e especificamente no Município de Marechal Cândido Rondon. Propagaram novas práticas de manejo com a lavoura, criações, estratégias de controle de pragas, sistemas e processos de manejo e conservação de solos, tidas como fundamentais para $\mathrm{o}$ aumento da produtividade. ${ }^{21}$

Estas informações, por vezes, foram difundidas pelas agências de extensão rural, educação e pesquisa, como também, por clubes 4-S que tinham como intuito levar sugestões de melhoramento e aumento da produtividade, vinculadas a proposta de aprimoramento do nível de vida da população rural.

Nos jornais locais, como "Rondon Comunicação", é possível visualizar uma grande aproximação entre a agência de extensão rural, no caso a Acarpa, e as cooperativas locais, como a Copagril. O referido jornal, em um recorte específico, publicado em 1974, apresentou informações sobre as atividades desenvolvidas pelos técnicos da Copagril e da Acarpa em diversos distritos da região.

Os técnicos da COPAGRIL e da ACARPA se deslocarão à diversos distritos do nosso município e mesmo em outros municípios pertencentes à área de responsabilidade da Cooperativa, com o objetivo de

\footnotetext{
${ }^{21}$ Informações consultadas no site da EMATER-PR disponível no site: http://www.emater.pr.gov.br/modules/conteudo/conteudo.php?conteudo=43 acessado em 11 de julho de 2014.
} 
levar novos conhecimentos tecnológicos e debater os problemas técnicos existentes com as atividades agropecuárias.

Esta caravana será composta de quatro engenheiros agrônomos, um médico veterinário, um zootecnista e um técnico agrícola. Em nove localidades proferirão palestras e estarão á disposição dos agricultores para informar ou responder sobre questões que foram levantadas pelos presentes.

Os temas a serem abordados mais pormenorizadamente versarão sobre a cultura da soja, nos seus mais diversos aspectos como: semente, variedades, inoculação, tratamento com fungicidas, adubação, calagem, inoculação, conservação do solo, tratamento contra pragas e doenças. Outros temas serão enfocados, tais como, diversificação da Propriedade, Alimentação e Manejo em Suinocultura, Higiene e Profilaxia na criação de suínos e liderança."

Nos dias atuais, quando o amadorismo na agricultura cede lugar à racionalidade e a agricultura de subsistência tende a empresa econômica e produtiva, o conhecimento e a atualização de modernas técnicas agronômicas é fundamental para o agricultor. Com esse pensamento os técnicos que prestam seus serviços nesta região dispuseram-se a realizar mais este trabalho e esperam receber o apoio necessário e receptividade. ${ }^{22}$

22 Jornal "Rondon Comunicação". Marechal Cândido Rondon, Ano: I; número: 30. 19 De Outubro De 1974. Assunto: caravanas técnicas. Jornal disponível para consulta no Centro de Documentação do Oeste do Paraná - CEPEDAL, localizado na Universidade Estadual do Oeste do Paraná - UNIOESTE, no campus de Marechal Cândido Rondon. 
Avaliando a informação proporcionada pelo jornal "Rondon Comunicação", podemos visualizar alguns dos objetivos fundamentais das agências de extensão rural, quais sejam; disseminar novos conhecimentos tecnológicos; novas formas de manejo com as sementes e tratamento das mesmas; conservação do solo; combate aos insetos. Ademais, pode-se dizer que o principal objetivo era que o agricultor desenvolvesse uma nova racionalidade, diferente daquela que ele apresentava anteriormente. Trata-se de uma racionalidade do lucro, como define Brum, cujo objetivo passa a ser a acumulação. Do mesmo modo, acrescenta que a agricultura passa a ser uma atividade crescentemente empresarial e se transformou num importante mercado para máquinas e insumos modernos produzidos pela indústria. Diga-se de passagem, trata-se de multinacionais.

Deste modo, uma maneira de conquistar o agricultor e convencê-lo a adotar novas técnicas agrícolas, aumentar sua produtividade e como provável consequência o seu lucro, era através das visitas feitas pelos técnicos da Acarpa e da Copagril aos trabalhadores rurais. No entanto, estas agências esperavam receber apoio e atenção por parte dos agricultores. Assim, também utilizavam os meios de comunicação que eram os Jornais locais, como uma tentativa de disseminar essa nova racionalidade.

Além das atividades desenvolvidas pela Acarpa e pela Copagril, os clubes 4-S também desenvolveram seus trabalhos de extensão nesta região, principalmente com jovens, geralmente filhos de 
agricultores. Esses clubes eram outra alternativa para convencer os agricultores a adotarem as novas tecnologias. Desenvolveram um trabalho "educativo" relacionado ao manuseio dos novos equipamentos, cujo alvo era os jovens, futuros empresários rurais.

O processo da "modernização" agrícola na região estudada além de ter impactado e modificado as relações sociais de produção, transformou as técnicas de produção, como foi discutido anteriormente. O Jornal "Rondon Comunicação" expressou o impacto dessas transformações capitalistas nas próprias condições de vida do meio rural.

Foi então que surgiu o cultivo da soja e, decorridos alguns anos, tivemos uma modificação violenta nas condições de vida do meio rural, com reflexo em todos setores de atividade, quer comércio, indústria ou atividades privadas. Hoje, a mecanização da lavoura tornou a agricultura num rendoso negócio, atraindo a atenção de todos que tenham conhecimento do que se faz em nosso município, bem como em toda a região do oeste do Paraná.

Tudo isso se deve a versatilidade de nossos agricultores, ou seja a tendência que possuem de adotar a técnica que lhes proporcione melhores resultados. O meio rural de nosso município se caracteriza pela agricultura em franco desenvolvimento, modernas técnicas, manejos adequados e agricultores que procuram saber e aplicar as renovações agrícolas e vão mais além, com um bom esclarecimento sobre mercado interno, 
e até externo, dos principais produtos agrícolas, regionais. Estas são as características que os diferencia das demais regiões brasileiras que, em geral mal informados persistem em não aceitar as palavras dos Engenheiros Agrônomos e continuam numa agricultura rudimentar, em consequências paralisam no tempo, constituindo o principal entrave ao desenvolvimento agropecuário brasileiro." 23

O meio rural do município de Marechal Cândido Rondon é apresentado pelo referido jornal em 1975 como avançado em relação a outras regiões do Brasil. Essa era a imagem que os meios de comunicação e os técnicos agrícolas pretendiam comunicar, uma vez que poderia influenciar no modo como as pessoas percebiam o desenvolvimento do município e do meio rural rondonense. A tentativa também era de mostrar uma opinião positiva do processo de "modernização" da agricultura local e desenvolver uma maior credibilidade de suas ações.

O trecho analisado também permite identificar que as propostas difundidas pelas agências de educação e de pesquisa, apresentadas nos jornais locais, tinham o intuito de levar sugestões de melhoramento da produtividade e do nível de vida da população rural. Tais práticas eram sustentadas na proposta de que a adoção de novas

\footnotetext{
${ }^{23}$ Jornal "Rondon Comunicação". Marechal Cândido Rondon, Ano: II; Número: 52. 22 De Março de 1975. Assunto da fonte: O Progresso que vem da terra. Jornal disponível para consulta no Centro de Documentação do Oeste do Paraná CEPEDAL, localizado na Universidade Estadual do Oeste do Paraná - UNIOESTE, no campus de Marechal Cândido Rondon.
} 
formas de trabalho, manejo com a terra e com a produção seriam responsáveis por melhorar a vida daqueles que adotassem os novos métodos difundidos, pois como o próprio jornal apresentou os técnicos relacionados às empresas de extensão rural, além de oferecer novas possibilidades técnicas, possuíam o conhecimento complementar e necessário sobre as oscilações dos produtos no mercado. Trata-se, também, de uma estratégia de integração ao mercado.

Todo este modelo posto em prática desde o sul até o norte brasileiro, não só contribui com o desenvolvimento da agricultura, mas também para a valorização do homem do campo. Com maiores recursos financeiro e a assistência técnica, o homem recebe condições humanas de trabalho e progresso e o mais importante, a informação tão necessária nos dias de hoje.

O trabalho conjunto da EMBRATER, cooperativas e outros órgãos como INAN, Instituto Nacional de Alimentação e Nutrição, fazem com que o nosso agricultor de hoje seja homem tão bem assistido como homem dos centros urbanos. Os meios de comunicação e a eletrificação rural muito tem contribuído com este trabalho.

Apesar de nos caracterizarmos por uma agricultura não muito tecnificada, as condições de vida no meio rural, hoje, difere, e bastante, de uns dez anos atrás. A que devemos isto? Em primeiro lugar a iniciativa governamental que tem criado inúmeros programas de desenvolvimento, com financiamentos a longo prazo e juros baixos; em segundo lugar, as cooperativas e órgãos de assistência Técnica que conduzem estes programas até a lavoura e em terceiro, ao agricultor que tem tido interesse em 
melhorar a sua propriedade, aderindo-se facilmente aos programas.

Esta interação, ou trabalho conjunto é característica de que estamos desenvolvendo a nossa agricultura e quanto mais o agricultor colaborar na técnificação da lavoura mais receberá sob a forma de assistência Técnica e Estímulos do Governo. ${ }^{24}$

As propostas modernizantes apresentadas, como se pode concluir a partir da citação anterior, apresentaram uma visão relativamente conservadora da questão agrária. Revela-se, ademais, como uma estratégia de inserção dos pequenos produtores a lógica de mercado. Na citação observa-se, também, que a valorização do homem do campo só ocorre a partir do momento em que ele "colabora" através da tecnificação de sua lavoura e integra-se, por fim, aos anseios da circulação de mercadorias do meio urbano. Consequentemente, ao adotar essas novas tecnologias o trabalhador rural melhoraria a sua propriedade, receberia maior assistência do governo e dos técnicos agrícolas, exímios portadores dos conhecimentos necessários para a implantação do processo.

Maria Yeda Linhares, em sua obra "Terra prometida: uma história da questão agrária no Brasil" avaliou que as visões conservadoras da questão agrária davam ênfase, e ainda o fazem, aos

\footnotetext{
${ }^{24}$ Jornal "Rondon Comunicação". Marechal Cândido Rondon. Ano: III; Número: 99; Data: 06 De Março De 1976. Assunto: Assistência Técnica Ao Meio Rural Terá 535 Milhões Em 1976. Jornal disponível para consulta no Centro de Documentação do Oeste do Paraná - CEPEDAL, localizado na Universidade Estadual do Oeste do Paraná - UNIOESTE, no campus de Marechal Cândido Rondon.
} 
aspectos técnicos, com o objetivo de despolitizar o problema e até mesmo, transferir para o trabalhador rural a carga da sua pobreza. ${ }^{25}$ Deste modo, esse pensamento conservador sobre o trabalhador do campo, leva o fortalecimento de estereótipos como, por exemplo, "aquele que não adota aos novos métodos passa a ser considerado atrasado e/ou ignorante".

O aumento da produtividade, o "progresso" e "desenvolvimento" da agricultura, mediados por certos conhecimentos restritos ao panorama técnico era um dos principais objetivos dos órgãos governamentais e não governamentais, cooperativas e outras instituições, através da estratégia da "modernização" agrícola. A utilização de métodos mais modernos, técnicas, equipamentos e insumos era um objetivo a ser realizado. Nesse sentido, como vimos anteriormente, os meios utilizados para informar, ou até mesmo convencer que a "modernização" era o caminho a ser seguido foram os canais de comunicação, como por exemplo, jornais locais e regionais, cooperativas, sindicatos, associações de produtores, empresas privadas, entre outras organizações governamentais e não governamentais.

${ }^{25}$ LINHARES, Maria Yedda Leite. Terra prometida: uma história da questão agrária no Brasil. Rio de Janeiro: Campus, 1999, p.143. 


\section{Referências}

ALVES, Clovis Tadeu. A revolução verde na mesorregião noroeste do RS (1930-1970). Porto Alegre, 2003.

BRUM, Argemiro jacob. Modernização da Agricultura: Trigo e Soja. Ijuí, RS, 1988.

GOMES, Leonardo Ribeiro. O Jovem dos Clubes 4-S como elemento difusor da Modernização das Práticas agrícolas em Minas Gerais nas décadas de 1950 e 1960. UFMG. Minas Gerais. Artigo disponível no site

http://sbhe.org.br/novo/congressos/cbhe7/pdf/04-

\%20HISTORIA\%20DA\%20EDUCACAO\%20DAS\%20CRIANCAS\%20JOVENS\%20E\%20ADULTOS\%20NO\%20BRASIL/O\%20JOVE M\%20DOS\%20CLUBES\%204-S.pdf acessado em 11 de julho de 2014.

HOUTZAGER, Peter P. Os últimos cidadãos: conflito e modernização no Brasil rural (1964 - 1995). São Paulo, 2004.

LINHARES, Maria Yedda Leite. Terra prometida: uma história da questão agrária no Brasil. Rio de Janeiro: Campus, 1999,

SOUZA, Sirlei de Fátima. Tradição $\mathbf{x}$ modernização no processo produtivo rural: os Clubes 4-S em Passo Fundo (1950-1980). 
Dissertação (Mestrado na área de História Regional) - Universidade de Passo Fundo. Rio grande do Sul, 2003.

ZAAR, Miriam Hermi. A produção do espaço agrário da colonização à modernização agrícola e formação do Lago de Itaipu. Cascavel, 1999.

\section{Sites pesquisados}

\section{Emater:}

http://www.emater.pr.gov.br/modules/conteudo/conteudo.php?conteudo $=43$

IBGE:http://cidades.ibge.gov.br/painel/historico.php?lang=\&codmun= 411460\&search=parana|marechal-candido-rondon|infograficos:historico

\section{Fontes analisadas}

Jornal "Rondon Comunicação". Marechal Cândido Rondon, Ano: I; número: 30. Data: 19 De Outubro De 1974.

Jornal “Rondon Comunicação". Marechal Cândido Rondon, Ano: II; Número: 52. Data: 22 De Março de 1975.

Jornal "Rondon Comunicação". Marechal Cândido Rondon. Ano: III; Número: 99. Data: 06 De Março de 1976.

Jornal "O Alento". Marechal Cândido Rondon, Ano: I; Número: 12. Data: $13 / 10$ À 18/10/79. 